http://journal.uinsgd.ac.id/index.php/biodjati

\title{
IMMUNOINFORMATICS STUDY ON EARLY 4 PROTEIN OF Human papillomavirus TYPE 16 FOR CERVICAL CANCER VACCINE PEPTIDE CANDIDATE
}

\author{
Yani Suryani*1, Opik Taupiqurrohman ${ }^{2}$, Muhammad Yusuf $^{3}$, Toto Subroto ${ }^{4}$, Sukma Nuswantara $^{5}$ \\ Received : July 25, 2019 \\ Accepted : September 17, 2019 \\ DOI: 10.15575/biodjati.v4i2.5414 \\ ${ }^{1,2}$ Department of Biology, Faculty of \\ Science and Technology UIN Sunan \\ Gunung Djati; Jl. AH. Nasution 105 \\ Bandung, West Java, Indonesia 40614 \\ ${ }^{3,4}$ Department of Chemistry, Faculty of \\ Math and Science, Universitas Padj- \\ adjaran; Jl. Raya Bandung-Sumedang \\ Km. 21, Jatinangor, Sumedang, West \\ Abstract. The aims of this study were to carry out testing of the \\ early 4 protein of type $16 \mathrm{HPV}$ through immunoinformatics meth- \\ ods in an effort to get the peptide vaccine candidate for cervical \\ cancer. The software used are IEDB-AR, CABSdock and Accelrys \\ Discovery Study 4.5. Based on the analysis that sequence of ami- \\ no acid lysine, leucine, leucine, glycine, serine, threonine, tryp- \\ tophan, proline and threonine (KLLGSTWPT) and the sequence \\ of amino acid tyrosine, tyrosine, valine, leucine, histidine, leucine, \\ cysteine, leucine, alanine, alanine, threonine, lysine, tyrosine, pro- \\ line and leucine (YYVLHLCLAATKYPL) are peptide vaccine can- \\ didate for cervical cancer from the early 4 protein of HPV type 16
} Java, Indonesia 45363

${ }^{5}$ Pusat Penelitian Bioteknologi LIPI

Jl. Raya Jakarta-Bogor Km. 46, Cibinong, Bogor 16911, West Java
Keywords: cervical cancer, Early 4, Human papillomavirus, immunoinformatics, vaccine

e-mail:

*lyani.suryani@uinsgd.ac.id

²taupiqurrohman@fst.uinsgd.ac.id

3myusuf@unpad.ac.id

느subroto@unpad.ac.id

ssukma001@lipi.go.id

*Corresponding author

\section{Citation}

Suryani, Y., Taupiqurrohman, O., Yusuf, M., Subroto, T. \& Nuswantara, S. (2019). Study of Immunoinformatics on Early 4 Protein of Human papillomavirus Type 16 for Cervical Cancer Vaccine Peptide Candidate. Jurnal Biodjati, 4(2), 252-262

\section{INTRODUCTION}

Cervical cancer is one of the diseases with a very high mortality rate (Gonzalez et al., 2005). The causes of cervical cancer is a Human papillomavirus (HPV) infection. WHO reported that two types of HPV viruses that widely identified as attacker type 16 and 18 (WHO, 2019). Potential effort to solve cervical cancer is vaccinations. According to Bruni et. al. (2019) 94\% cases of cervical cancer in Indonesia are caused by type 16 of HPV, Thus during the development of cervical cancer, type 16 of HPV is the most potential target.

The most efficient method of developing vaccines is through the immunoinformatics method. The success of immunoinformat- 


\section{JURNAL BIDDJATI}

http://journal.uinsgd.ac.id/index.php/biodjati

ics methods has been proven (Li et al., 2015). The process of developing vaccines through immunoinformatics methods is by predicting the bond strength between the peptides of vaccine candidate from the protein of microorganism with the Major Histocompatibility Complex (MHC) proteins (MHC I and MHC II) (Taupiqurrohman et al., 2016). This is based on the mechanism of immune system activation that passes through the protein. Peptides that are strongly bound to MHC I will be able to activate cytotoxic $\mathrm{T}$ cells, while peptides that are strongly bound to MHC II will activate $\mathrm{T}$ helper cells. The next step of immune response after activation of cytotoxic $\mathrm{T}$ cells is the degradation of infected cells by these $\mathrm{T}$ cells while activated helper $\mathrm{T}$ cell antibodies will be formed (Sompayrac, 2008). Therefore, the prediction of peptide-MHC I and II interactions needs to be done in the process of finding peptide vaccine candidates. The prediction process involves binding affinity as an indicator. Affinity is the tendency of a substance to bind to another substance (Kim et al., 2012).

To obtain accurate bond predictions, three-dimensional visualization of interactions between the peptide and MHC I and II is required. Visualization of the three-dimensional structure of interactions between peptides and MHC or with other proteins is still limited to the crystal structure. Currently, computer programs are developed to predict the interaction of peptides-protein visually. The prediction method is known as molecular docking. This method develops along with the need to understand the important role of proteins in body cells. The protein visualization by molecular docking is needed to understand the role protein easier, as the results of the conventional molecular method are still limited (Kurcinski et al., 2015).

The vaccine developed through immunoinformatics must not have the similarity of genes or genomes between microorganisms where the vaccines will be developed with the human genome. This is to avoid the emergence of autoimmune diseases after vaccination. In the process of obtaining a vaccine candidate using the immunoinformatics method, it is protein from a vaccine source microorganism that being utilized, not the gene. However, it is important to examine the genes of candidate vaccine source microorganisms with the human genome (Taupiqurrohman et al., 2016).

All of HPVs, including type 16, have genomes which are divided into three main regions, namely the regulator, the late and the early. The late region is divided into two main parts namely Late 1 and Late 2 which are responsible for the formation of the viral capsid. While early is divided into seven parts, namely Early 1, Early 2, Early 3, Early 4, Early 5, Early 6 and Early 7 which are responsible for mastering and causing cancer in the host (Morshed et al., 2014). All genes in HPV produce the same name as the gene name. Suppose the Early 1 gene produces protein Early 1 and so on.

Early 4 genes HPV has a role in advanced infections when virions are made. These genes play an important role in maturation (viral maturation) and replication. Early 4 protein also affects cytoplasmic decay in cytokeratin tissue in human keratinocyte cells. Based on its function adjacent to cancer-causing genes in cervical cancer, it is necessary to test the Early 4 genes as a source of vaccine candidates. The aim of this study was to carry out testing of the Early 4 protein of type 16 HPV through immunoinformatics methods as an effort to get a peptide vaccine candidate for cervical cancer. 


\section{JURNAL BIDDJATI}

http://journal.uinsgd.ac.id/index.php/biodjati

\section{MATERIALS AND METHODS}

The tools used are a personal computer with specifications of the Intel ${ }^{\circledR}$ Celeron $\AA$ CPUN3060@1.60GHz,4.00GBRAM,64Bit System Operations, and 250 GB Hard disks.

The research material consisted of a sequence of amino acid E4 protein, webbased software workbench, IEDB-AR, CABSdock, and standalone software Accelrys Study Discovery 4.5, the sequence of amino acid peptide as control peptides from MHC I and II crystal structures, obtained from protein data bank (PDB) website.

\section{Research Procedure}

The research was carried out using a computational method with the following procedure, the amino acid sequence data of early 4 protein of HPV type 16 was compiled from the UniProt website. Furthermore, the protein homology process was carried out with the entire human genome in the workbench website (Fatima \& Desu, 2014). After the homology process was carried out, the MHC I and MHC II crystal structures were downloaded from the website http://www.rcsb.org.

The next step was to predict the sequence of the Early 4 protein of type $16 \mathrm{HPV}$ to get cervical cancer peptide vaccine candidate. The prediction process was carried out using IADB-AR software. The principal works were to look for sequences of peptides from Early 4 proteins that are strongly bound to MHC I and II. This software uses consensus algorithms with affinity energy values as an indicator (Kim et al., 2012).

While waiting for the prediction process, the process of downloading the MHC I and II crystal structures was carried out from http://www.rcsb.org (PDB code 2BNQ for MHC I and 1J8H for MHC II) and peptide separation was attached to the MHC I and
MHC II crystal structures using Accelrys Discovery Studio 4.5.

The next step was the molecular docking. The purpose of this step was to visualize the interaction between vaccine candidate peptides and MHC I and II. The molecular docking process was divided into two stages, namely the first process was validating CABSdock software by doing docking between peptides that have been separated from crystal structures by MHC I and II. The result is categorized as valid if it has an RMSD value below 3 (Kurcinski, et. al., 2015). The second process was molecular docking processes between peptides candidate using CABSdock software. The last step was the process of analyzing molecular docking results with Accelrys Discovery Studio 4.5 software.

\section{RESULTS AND DISCUSSION}

\section{The Sequence of Early 4 Protein}

Table 1 shows the sequence of amino acids from the early 4 protein of type $16 \mathrm{HPV}$. These proteins are composed of 94 amino acids.

\section{The Homology Process of Early 4 Protein with the Human Genome}

Based on the process in the website http://workbench.sdsc.edu/, the Early 4 protein do not have similarities/identities with the human genome as it produces an identical percentage of $0 \%$. This process is intended so that the resulting vaccine does not trigger an autoimmune response. Autoimmune is a specific immune response disorder that attacks the healthy cells, so if a peptide vaccine sourced from a protein similar to humans it might result in this response. The autoimmune response is usually induced by $\mathrm{T}$ cells and B cells respectively, or it can be by both. In some cases, autoimmune can result in loss 


\section{JURNAL BIDDJATI}

http://journal.uinsgd.ac.id/index.php/biodjati

of body tissue function (Bellone, 2005).

\section{Download MHC I and MHC II Crystal Structures}

The download process of MHC I and II crystal structures was carried out through the protein database website, http://www.rcsb.org or protein data bank (PDB). The PDB code used for MHC I is $2 \mathrm{BNQ}$ and $1 \mathrm{~J} 8 \mathrm{H}$ for MHC II (Taupiqurrohman, 2016).

\section{Prediction of the Amino Acid Sequence of Candidate Vaccine Peptides MHC I-Peptide}

The prediction was carried out using IEDB-AR (Vita et al., 2010) by utilizing amino acid sequences of E4 HPV type 16 proteins. IEDB-AR was the result of the development of the IEDB.
IEDB-AR works by using a consensus algorithm (SMMPMBEC and NetMHCpan). This algorithm was developed on the grounds that the combination method can produce the predictions that are far better than using a single method. In the process of predicting vaccine candidates, the algorithm produces a percentile score. Percentile scores are defined as the percentage of random peptides from the E4 protein bound to the MHC. The use of a consensus approach will result in a bond affinity score for peptides in the form of a median percentile score from different predictors (Kim et al., 2012). Table 2 and 3 is the result of IEDB-AR prediction. Amino acid sequence Lysine, Lysine, Valine, Glycine, Serine, Threonine, Tryptophan, Proline, and Threonine (KLLGSTWPT) is a predictive peptide vaccine candidate that can activate cytotoxic $\mathrm{T}$ cells (Table 2).

Table 1. The sequence of Amino Acids E4 Protein HPV type 16

\begin{tabular}{cc}
\hline Gene & Sequence \\
\hline \multirow{2}{*}{ E4 } & YYVLHLCLAATKYPLLKLLGSTWPTTPPRPIPKPSPWAPKKHRRLSS \\
& DQDQSQTPETPATPLSCCTETQWTVLQSSLHLTAHTKDGLTVIVTLHP \\
\hline
\end{tabular}

(Source: http://www.uniprot.org)

Tabel 2. Prediction of candidate vaccine peptide sequences based on their bond with MHC I

\begin{tabular}{cccccccccc}
\hline \multirow{2}{*}{ Allele } & \multicolumn{2}{c}{$\begin{array}{c}\text { Location of } \\
\text { Sequence }\end{array}$} & \multirow{2}{*}{ Long } & Peptide & $\begin{array}{c}\text { Score } \\
\text { Percentile }\end{array}$ & & & \multicolumn{3}{c}{$\mathrm{IC}_{50}(\mathrm{M})$} \\
\cline { 2 - 6 } \cline { 7 - 10 } & Start & End & & & ann & SMM & Comblib \\
\hline HLA-A*02:01 & 17 & 25 & 9 & KLLGSTWPT & 0.6 & 6 & 47.55 & $9.02 \times 10^{-6}$ \\
\hline
\end{tabular}

Tabel 3. Prediction of candidate vaccine peptide sequences based on their association with MHC II

\begin{tabular}{ccccccccc}
\hline \multirow{2}{*}{ Allele } & \multicolumn{2}{c}{$\begin{array}{c}\text { Location of } \\
\text { Sequence }\end{array}$} & & & & \multicolumn{3}{c}{ IC50 (M) } \\
\cline { 2 - 4 } & Start & End & & Pong & Score Percentile & $\begin{array}{c}\text { Comb. } \\
\text { blib }\end{array}$ & smm & nn \\
\hline $\begin{array}{c}\text { HLA- } \\
\text { DRB1*01:01 }\end{array}$ & 1 & 15 & 15 & $\begin{array}{c}\text { YYVLHLCL } \\
\text { AATKYPL }\end{array}$ & 6,39 & 0,01 & 62 & 11,6 \\
\hline
\end{tabular}




\section{JURNAL BIDDJATI}

http://journal.uinsgd.ac.id/index.php/biodjati

Selection of candidate vaccines (peptides) is based on the value of the smallest percentile score. The smaller the percentile score the better the bond (Kim et al., 2012). The percentile score is a term that refers to the percentage score that is equal to or less than the given value, in this case, the intended value is the inhibitor concentration 50 ( $\mathrm{IC}_{50}$ ) value.

Inhibitor Concentration $50\left(\mathrm{IC}_{50}\right)$ is a $50 \%$ concentration of the part of the peptide bound to MHC. This binding (energy) capability can be described as the ratio between standard IC $\mathrm{C}_{50}$ peptides and test peptides (Sette et al., 1994). Determination of $\mathrm{IC}_{50}$ values in this software uses the consensus algorithm method, which is a combination of ANN (Artificial Neural Network) algorithm, Stabilized Matrix Method (SMM) and Comblib (Combinatory Library) algorithm. ANN is a computer algorithm that mimics the work of the brain system. ANN consists of a collection of simple units that form communication networks like neurons in the brain. The unit will respond if there is an input signal. The unit referred in this algorithm is an amino acid residue from MHC I. While the signal is a protein residue (peptide) which will be predicted in this case E4 protein with a response in the form of the $\mathrm{IC}_{50}$ value generated (Fleri, 2012).

Stabilized Matrix Method is a method for calculating the affinity peptide matrix bound to MHC (Fleri, 2012). Whereas combinatory library is an affinity measurement method from a combination of various peptides (protein residues tested) against MHC. The three methods work together to produce better accuracy. Furthermore, the value produced by each method is ranked and a percentile score is generated.

\section{MHC II-Peptide}

The amino acid sequence of Tyrosine, Tyrosine, Valine, Leucine, Histidine, Leu- cine, Cysteine, Leucine, Alanine, Alanine, Alanine, Threonine, Lysine, Tyrosine, Proline, and Leucine (YYVLHLCLAATKYPL) are candidate predictive peptides of vaccines that can reactivate Helper T cells. (Table 3).

Determination of $\mathrm{IC}_{50}$ peptide-MHC II had similarities with the peptide-MHC I which used a consensus algorithm consisting of NN-align (Neural Network Alignment), SMM-align (Stabilization Matrix Alignment Method), and Comb.blib (Combinatory Library). The choice of this consensus method is recommended by the IEDB-AR program in the predisposing process.

$\mathrm{NN}$-align is an algorithm compiled to predict MHC II peptide bonds with the same principle as ANN. The NN-align is able to predict the affinity of peptides against MHC II, and identify binding-core peptides, namely peptide fragments that interact with the main bonding sac of MHC II (binding groove). While SMM-align is a method of predicting MHC II-peptide bonds from certain peptide sequence patterns based on the matrix (Position-Specific Weight Matrix). The result of the SMM-align method is $\mathrm{IC}_{50}$. While the comb.lib method uses a peptide position scanning approach in a positional scanning combinatorial libraries to systematically pool random peptides to determine the contribution of each amino acid per nine peptide positions to MHC II peptide bonds. Each pool contains 9 mer peptides with one residue remaining in one position. Each residue of 20 natural amino acids is in the main chain of 9 mer, so the entire database contains 180 mixed peptides. Competitive binding assays were carried out to determine $\mathrm{IC}_{50}$ values for each pool. The final result of this method is the prediction of new 9 mer peptide bonds from 20 score matrices against MHC II (Fleri, 2012). As in the prediction of MHC-peptide I, the $\mathrm{IC}_{50}$ value generated by each method was then ranked 
Jurnal Biodjati 4(2):252-262, November 2019

\section{JURNAL BIDDJATI}

http://journal.uinsgd.ac.id/index.php/biodjati

and the result is a percentile score. A small percentile score indicates that the $\mathrm{IC}_{50}$ value generated by these methods is possessed by a small number of peptide sequences of type 16 EV HPV proteins that are predicted, therefore the smaller the percentile score the stronger the bond.

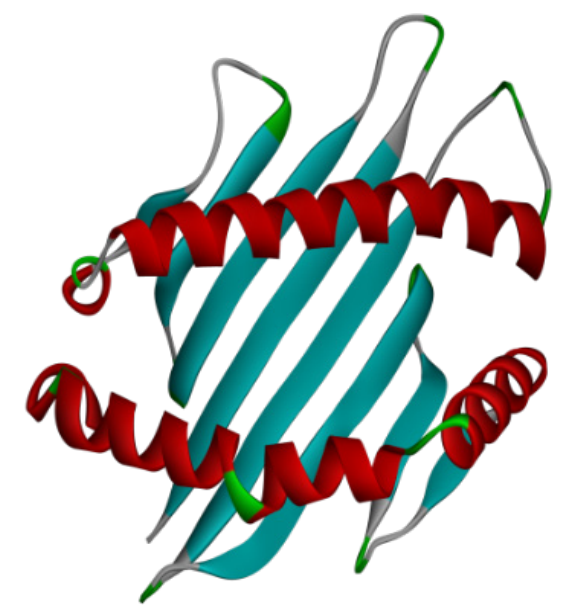

Separation of Peptide-MHC Crystal Structures

The separation between MHC peptides (MHC I and MHC II) on MHC I and MHC II crystal structures has been downloaded from the database using Accelrys Discovery Studio 4.5 (Figure 1).

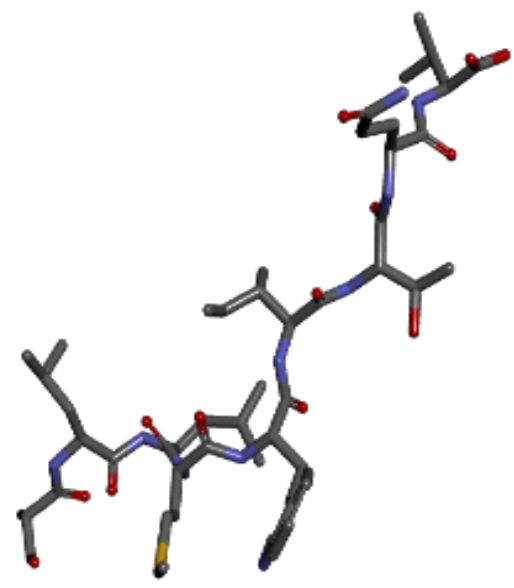

Figure 1. Result of Separation of MHC by Using Accelrys Discovery Studio

Table 4. Results of Validation of CABSdock Software

\begin{tabular}{cccc}
\hline No & $\begin{array}{c}\text { Kode PDB } \\
(\text { Crystal structure })\end{array}$ & RMSD $(\AA)$ & A sequence of peptide crystal structure \\
\hline 1 & $2 \mathrm{BNQ}$ & 0.85 & SLLMWITQV \\
2 & $1 \mathrm{~J} 8 \mathrm{H}$ & 1.55 & PKYVKQNTLKLAT \\
\hline
\end{tabular}

Table 5. Information on molecular docking energy results

\begin{tabular}{ccccccc}
\hline & & & \multicolumn{2}{c}{ PDB Receptor } & \multicolumn{2}{c}{ Energy of Interaction } \\
\cline { 4 - 7 } No & Gene & $\begin{array}{c}\text { Peptide Vaccine } \\
\text { Candidate }\end{array}$ & $\begin{array}{c}\text { MHC I } \\
(\text { Allele } \\
\text { HLA-A*02:10) }\end{array}$ & $\begin{array}{c}\text { MHC II } \\
(\text { Allele HLA- } \\
\text { DRB1*01:01) }\end{array}$ & $\begin{array}{c}\text { Peptide Vaccine } \\
\text { Candidate } \\
(\mathrm{Kcal} / \mathrm{mol})\end{array}$ & $\begin{array}{c}\text { Peptide Control } \\
(\text { Kcal/mol })\end{array}$ \\
\hline 1 & E4 & KLLGSTWPT & 2BNQ & - & -121.00 & -192.80 \\
2 & E4 & YYVLHLCLAATKYPL & - & $1 \mathrm{~J} 8 \mathrm{H}$ & -204.80 & -185.40 \\
\hline
\end{tabular}

\section{Molecular Docking}

\section{Validation of CABSdock Software}

Validation was carried out to find out the quality of the software method used. The quality assessment was based on the results of repeating an MHC-peptide complex found in PDB by the selected software. The method was categorized as good if the Suryani et al. docking results have a value of intersection. The value intersection was showed by root mean standard deviation (RMSD) value. RMSD value is a value that describes the position of the ligand at the receptor after reassembling using the molecular docking method. According to Kurcinski et al. (2015) that RMSD value below $3 \AA$ showed a good or 


\section{JURNAL BIDDJATI}

http://journal.uinsgd.ac.id/index.php/biodjati

valid docking method. Table 4 showed the result of CABSdock software validation. Based on the result, CABSdok is a valid method because the RMSD value is below $3 \AA$, which is $0.85-1.55 \AA$.

\section{Docking Peptide of Vaccine Candidate with MHC I and II}

The CABSdock software produced 10 conformational predictions with each conformation having 1000 conformational approaches. Each conformational prediction produces different energy interactions with each other. What is displayed in the table is the interaction energy with the best conformation. The interaction energy produced by CABSdock is the accumulation of Columb and Linneard Jones interactions. The calculation process is carried out during the molecular tethering process (Blaszczyk et al., 2016). Table 5 shows the energy of molecular docking results between vaccine candidate peptides and MHC with control (crystal structure).

\section{Conformation Analysis of Molecular Dock- ing Results \\ Conformations of Peptide Vaccine Candi- date with MHC I}

The energy affinity value resulting from the molecular docking process against peptides vaccine candidate with MHC I was higher than the crystal structure affinity energy (2BNQ) which are $121.00 \mathrm{Kcal} / \mathrm{mol}$ and $192.00 \mathrm{Kcal} / \mathrm{mol}$, respectively. This value indicates that the interaction in the conformation of peptide vaccine candidate-MHC I is relatively lower (not strong) compared to the control (crystal conformation). However, in terms of the location of the peptide bound to MHC I, the peptide vaccine candidate has the same area as the crystal structure peptide (Figure 2).

Based on the results of the analysis using the Accelrys Discovery Studio in the conformation of the MHC I-peptide vaccine candidate a conventional hydrogen bond was formed between amino acid residues 77ASP189THR with a distance of $3.28 \AA$. The interaction of carbon-hydrogen with the amino acid 66 LYS-184GLY with a distance of 3.63 $\AA$ was also formed A hydrogen donor interaction was also formed between the amino acid 167TRP-181LYS at a distance of 3.27 $\AA$. Meanwhile, in the control conformations of, only conventional hydrogen bonds were formed, namely between the amino acids 97ARG-183 Leu with distance $2.68 \AA$, and 26GLY-189VAL with a distance of $3.13 \AA$ (Figure 3).

In Figure 4, there was a hydrophobic interaction formed in the conformation of MHC I-peptide vaccine candidate involving pi-electron donors The interaction formed between the amino acid 147TRP-187TRP at a distance of $4.60 \AA$, 99TYR-182LEU at a distance of $5.32 \AA, 114 \mathrm{HIS}-188 \mathrm{PRO}$ at a distance of $3.92 \AA, 147 \mathrm{TRP}-188 \mathrm{PRO}$ at a distance of $4.88 \AA, 167$ TRP-181LYS at a distance of $5.43 \AA, 156 \mathrm{LEU}-187 \mathrm{TRP}$ at a distance of 3.31, 126 LEU-187TRP at a distance of $4.71 \AA, 153 \mathrm{ALA}-187 \mathrm{TRP}$ at a distance of $5.33 \AA, 33$ PHE-181LYS at a distance of 4.76 $\AA$ and $156 \mathrm{LEU}-187 \mathrm{TRP}$ at a distance of 3.89 $\AA$. In addition, there were also Alkyl interactions between 66LYS-183LEU at a distance of $3.95 \AA, 184 \mathrm{CYS}-182 \mathrm{LEU}$ at a distance of $4.10 \AA$, 5MET-181LYS at a distance of 4.76, and 124ILE-188PRO at a distance of $4.62 \AA$.

Figure 4 also shows, the formation of an interaction involving pi-electron donor and sigma-pi between 33PHE-189VAL acid with a distance of $3.91 \AA$, 99TYR-184MET with a distance of $4.11 \AA$, 114HIS-182LEU with a distance of $4.49 \AA$, 114HIS-184MET with a distance of $3.67 \AA, 116 \mathrm{TYR}-182 \mathrm{LEU}$ with a distance of $5.34 \AA, 147 \mathrm{TRP}-182 \mathrm{LEU}$ with 
Jurnal Biodjati 4(2):252-262, November 2019

\section{JURNAL BIDDJATI}

http://journal.uinsgd.ac.id/index.php/biodjati

a distance of $4.82 \AA, 167$ TRP-18ILE with a distance of $5.41 \AA$, 171TYR-189VAL with a distance of $5.06 \AA$, 66LYS-185TRP with a distance of $4.70 \AA$, and 66LYS-185TRP $4.66 \AA$ in control conformation. In addition, there was an alkyl interaction between the 5MET-186ILE amino acids, 28VAL-189VAL, 124ILE-182LEU, 156LEU-184MET, 160LEU-184MET, 164CYS-186ILE and 5MET-189VAL with a distance of $4.52 \AA$, $4.44 \AA, 4,50 \AA, 3,86 \AA, 4.82 \AA, 4.08 \AA, 4.77$ $\AA$ respectively.

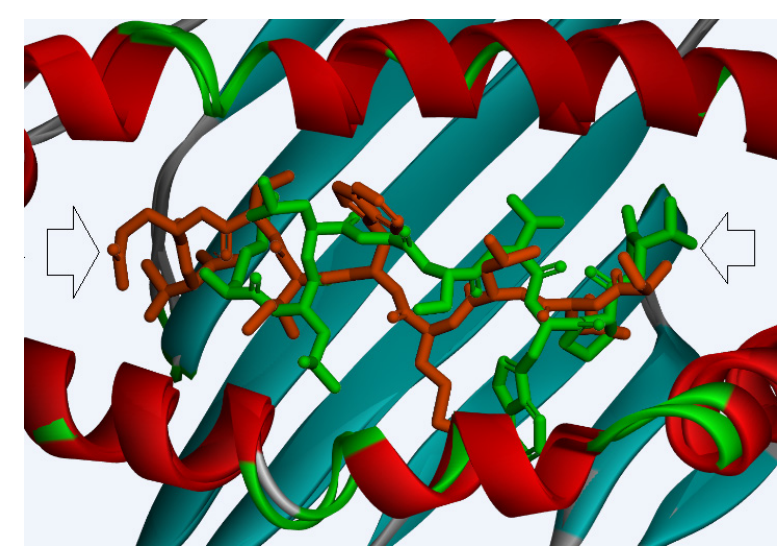

Figure 2. Result of Molecular Docking of Peptide-MHC I $($ Red = Control Peptide; Green $=$ Predicted Peptides)

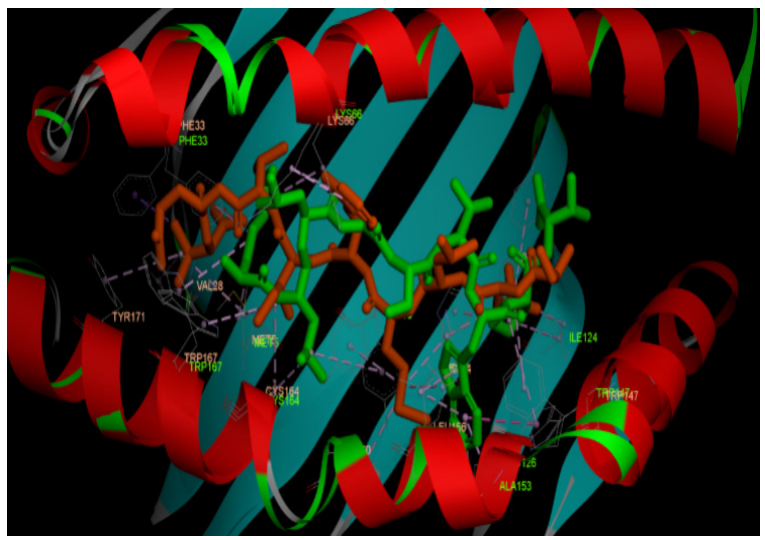

Figure 4. Hydrophobic Interaction Formed between Prediction of Peptide-MHC I (Red = Control Peptide; Green $=$ Predicted Peptides)
Figure 5. shows a salt bridge formed between amino acids 97ARG-189THR with a distance of $2.77 \AA$, 63GLU-181LYS with a distance of $3.71 \AA$, and 63GLU-181LYS with a distance of $3.74 \AA$. In addition, there is an interaction between the 167TRP-181LYS at a distance of $3.27 \AA$ and interaction between the 116TYR-189THR at a distance of 4.02 $\AA$ in the conformation of the MHC I-peptide vaccine candidate. Meanwhile, in the control confirmation, there is only a load interaction extract which is formed between amino acid SER181-ASP77 at a distance of $5.00 \AA$.

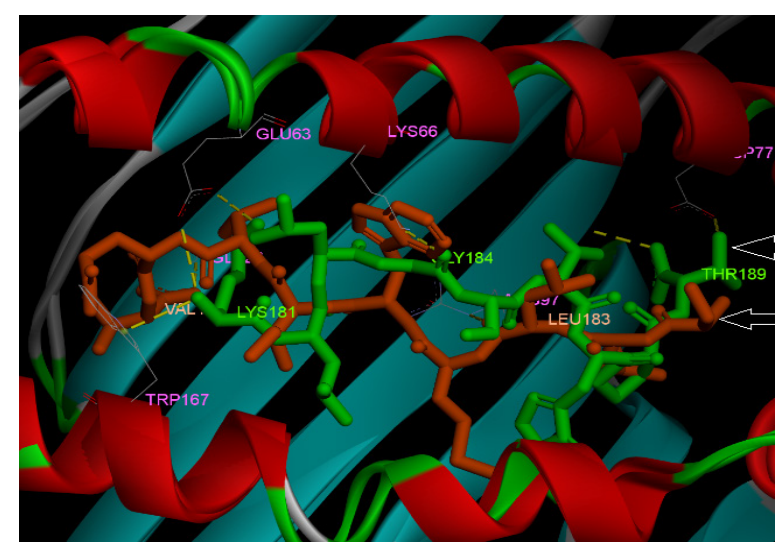

Figure 3. Hydrogen Bonds Formed between Prediction of Peptide-MHC I (Red = Control Peptide; Green $=$ Predicted Peptides)

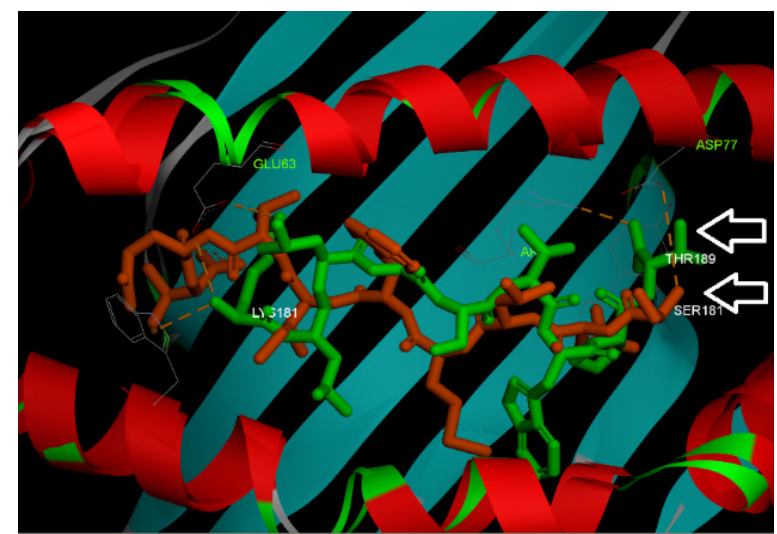

Figure 5. Electrostatic Interaction Formed between Prediction of Peptide-MHC I (Red = Control Peptide; Green $=$ Predicted Peptides $)$ 


\section{JURNAL BIDDJATI}

http://journal.uinsgd.ac.id/index.php/biodjati

\section{Conformations of Peptide Vaccine Candi- date with MHC II}

Based on Table 5, the energy affinity values resulting from the molecular docking process of the conformations MHC II-peptide vaccine candidate was lower $(-204.80 \mathrm{Kcal} /$ mol) than the control (crystal structure) affinity energy, which was $-185.40 \mathrm{Kcal} / \mathrm{mol}$. This value indicates that the interaction in the $\mathrm{MHC}$ II-peptide vaccine candidate conformations is stronger than the control conformation. In addition, the peptide vaccine candidate also lies on the same active site as the crystal peptide (Figure 6).

The Figure 7 shows in the conformations of MHC II-peptide vaccine candidate two hydrogen bonds are formed, namely between the amino acid 371THR-61ASN with distance $3.28 \AA$, and 372LYS-61ASN with distance $3.53 \AA$. While the conformations of the control forms eight hydrogen bonds, namely between the 68ASN-368THR residue within $2.76 \AA$, 366GLN-206ASP within 3.01 $\AA$, 373THR-68ASN within $3.65 \AA$ (hydrogen carbon interaction), 249LYS-363TYR at 3.23 $\AA$ (hydrogen carbon interaction), 365LYS206ASP runs $3.20 \AA$ (hydrogen carbon interaction), 363TYR-204PHE is 3.95 (donor pi), 365LYS-208TYR is $4.20 \AA$ (pi donor) and $367 \mathrm{ASN}-239 \mathrm{TRP}$ is $3.67 \AA$ (donor pi).

Figure 8 show the result of hydrophobic interaction analysis on MHC II- peptide vaccine candidate conformations and control conformation. In MHC II-peptide vaccine candidate conformation, interactions occur between amino acids 375LEU-238TYR with a distance of $3.75 \AA$ (pi sigma interaction), 365HIS-256TYR with a distance of $3.95 \AA$ (pi-pi interaction), 191HIS-365HIS at $4.93 \AA$ (interaction of pi form T), 189VAL-372LYS is $4.47 \AA$ (alkyl interaction), 369ALA-245LEU $4.77 \AA$ (alkyl interaction), 370ALA-249LYS is $3.94 \AA$ (alkyl interaction), 191HIS-ALA370 spaced $5.46 \AA$ (pi alkyl interaction), 239TRP369ALA $4.90 \AA$ (pi alkyl interaction), 363VAL-31PHE is $3.76 \AA$ (pi sigma interaction), 364LEU-53PHE is $3.57 \AA$ (pi sigma interaction), 68ASN-373TYR is 5.03 (pi amide interaction), 51ALA-363VAL is $4.57 \AA$ (alkyl interaction), 64 VAL-372LYS border is 4.23 $\AA$ (alkyl interaction), 21PHE-364LEU is 4.70 (pi alkyl interaction), 23PHE-363LEU is 4.53 (pi alkyl interaction), 373TYR-64VAL is 4.85 $\AA$ (alkyl pi interaction), and 373TYR-67ALA is $5.00 \AA$ (alkyl pi interaction).

Meanwhile in the control conformation, a hydrophobic interaction was formed between amino acid residues 189VAL-364VAL with a distance of $4.65 \AA$ (interaction of alkyl), 189VAL-365LYS within 5.20 A (alkyl interaction), 208TYR-365LYS within 4.62 $\AA$ (interaction alkyl pi), 238TYR-372ALA is $4.01 \AA$ (pi alkyl interaction), 239TRP365LYS is $4.70 \AA$ (alkyl pi interaction), 256TYR-362LYS is $5.31 \AA$ (alkyl pi interaction), 363TYR-252ALA is spaced $4.25 \AA$ (pi alkyl interaction), 58ALA-361PRO is $4.36 \AA$ (alkyl interaction), 64VAL-371LEU is $5.26 \AA$ (alkyl interaction), 21PHE-361PRO is $4.17 \AA$ (alkyl pi interaction) and 31PHE-361PRO is $4.73 \AA$ Å (alkyl pi interaction).

The conformations of MHC II-peptide vaccine candidate produced electrostatic interactions in the form of a salt bridge between amino acids $372 \mathrm{LYS}-65 \mathrm{ASP}$ as far as $3.00 \AA$, 75ARG-375LEU as far as $4.69 \AA$ and interaction of attractive charges between amino acids 372LYS-10GLU as far as $4.33 \AA$ (Figure $9)$. Whereas in the control conformation the electrostatic interaction was formed between the amino acid 365LYS-235ASP within 3.75 $\AA$ (salt bridge), 365LYS-208TYR within 4.20 $\AA$ and 365LYS-215TYR within $4.55 \AA$ (interaction). 


\section{JURNAL BIDDJATI}

http://journal.uinsgd.ac.id/index.php/biodjati

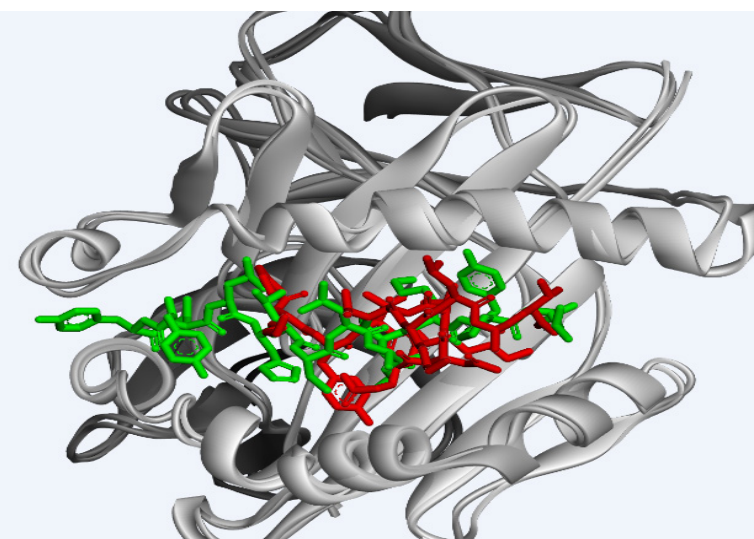

Figure 6. Result of Molecular Docking of Peptide-MHC II (Red = Control Peptide; Green $=$ Predicted Peptides)

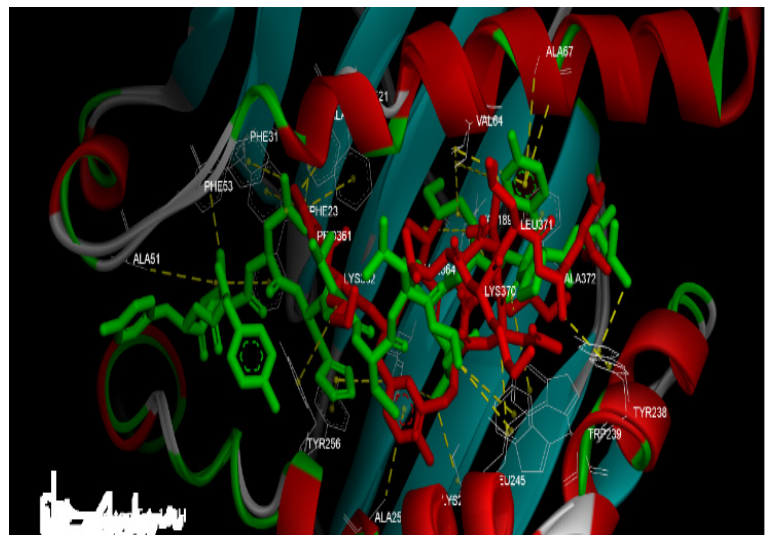

Figure 8. Hydrophobic Interaction Formed between Prediction of Peptide-MHC II (Red = Control Peptide; Green $=$ Predicted Peptides)

\section{ACKNOWLEDGMENTS}

Many thanks to the UNPAD computational laboratorium team, who help with this research.

\section{REFERENCES}

Bellone M. (2005). Autoimmune Disease: Pathogenesis. Italy: John Wiley \& Sons (http://www.els.net).

Blaszczyk, M., Mateusz, K., Maksim, K., Lukasz, W., Aleksander, D. \& Andrzej K. (2016). Modeling of Protein-Peptide Interactions Using The CABS-dock Suryani et al.

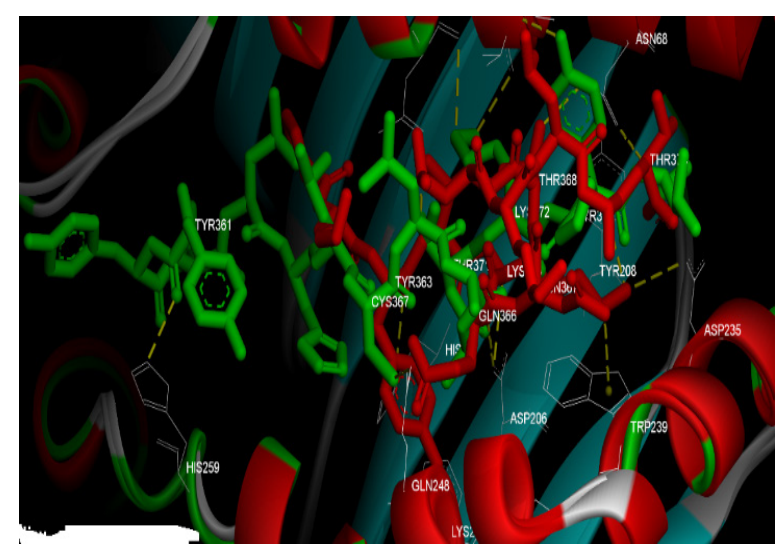

Figure 7. Hydrogen Bonds Formed between Prediction of Peptide-MHC II (Red = Control Peptide; Green $=$ Predicted Peptides)

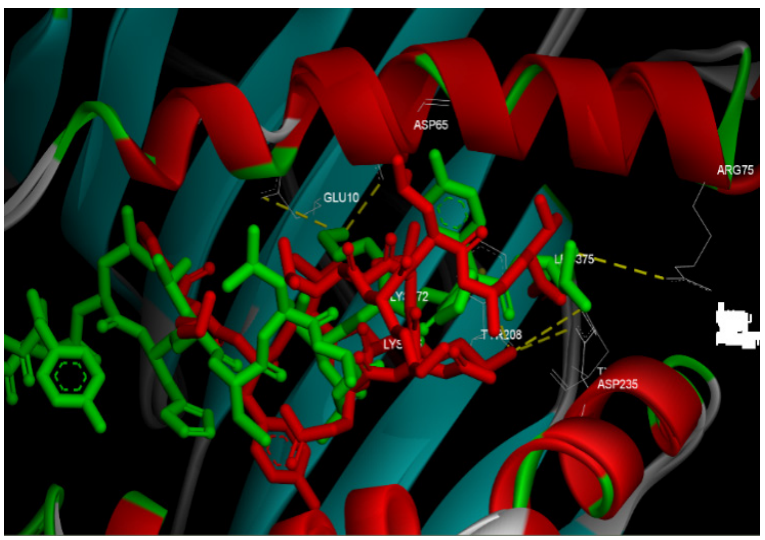

Figure 9. Electrostatic Interaction Formed between Prediction of Peptide-MHC II (Red = Control Peptide; Green = Predicted Peptides)

Web Server for Binding Site Search and Flexible Docking. Method. 93, 72-83.

Bruni, L., Albero, G., Serrano, B., Mena, M., Gómez, D., Muñoz, J., Bosch, FX. \& de Sanjosé, S. (2019). ICO/IARC Information Centre on HPV and Cancer (HPV Information Centre). Summary Report. Human Papillomavirus and Related Diseases in Indonesia.

Fatima, S. S. \& Desu, J. (2014). Proteome Analysis and Antigenic Peptide Prediction of Beta Corona Cirus, A Cause of MERS. Helix, (5), 590-583.

Fleri, W. (2012). T-Cell epitopes - MHC Class

I Binding Prediction Tools Description. 


\section{JURNAL BIDDJATI}

http://journal.uinsgd.ac.id/index.php/biodjati

Retrieved from http://help.iedb.org/ entries/21903572-t-cell-epitopes-mhcclass-ii-binding-prediction-tools-description.

Fleri, W. (2012). T-Cell epitopes - MHC Class II Binding Prediction Tools Description IEDB Solutions Center. Retrieved from http://help.iedb.org/entries/21903572-tcell-epitopes-mhc-class-i-binding-prediction-tools-description.

Gonzalez, A. D., Marcela, L., Myrna, C., Lucely, C., Claudia, A. \& Eduardo, C. (2005). Epigenetics of Cervical Cancer. An Overview and Therapeutic Perspectives. Molecular Cancer, 4(38), 1-24.

Kim, Y., Julia, P., Zhanyang, Z., Dorjee, T., Peng, W. \& Jason, G. (2012). Immune Epitope Database Analysis Resource. Nucleic Acids Research, 40, 525-530.

Kurcinski, M., Michal, J., Maciej, B., Andrzej, K. \& Sebastian, K. (2015). CABS-Dock Web Server for the Flexible Docking of Peptides to Proteins without Prior Knowledge of the Binding Site. Nucleic Acids Research, 1-6.

Li, B., Xianfang, Z., Chuancui, H. \& Yunxia, C. (2015). Human papillomavirus Genome-Wide Identification of T-cell Epitopes for Peptide Vaccine Development Against Cervical Cancer: An Integration of Computational Analysis and Experimental Assay. $J$ Computation Biol, 22(10), 962-974.
Morshed, K., Dorota, P., Marcin, S. \& Małgorzata, P. (2014). Human Papillomavirus (HPV) - Structure, Epidemiology and Pathogenesis. Otolaryngology Polska. Elsevier. pp. $213-219$.

Sompayrac, L. How the Immune System Work. 3ed Edition. (2008). Massachussetts: Well Publishing.

Taupiqurrohman, O. (2016). Desain dan Pengembangan Vaksin Human papillomavirus Tipe 16 Berbasis Epitop Secara In Silico. Thesis. Bandung. Universitas Padjadjaran.

Taupiqurrohman, O., Yusuf, M., S. Nuswantara, T. \& Subroto, T. (2016). Potensi Gen Oncoprotein Human Papillomavirus Tipe 16 Sebagai Kandidat Vaksin Kanker Serviks. MKB, 48(35), 84- 91.

Vita, R., Laura, Z., Jason, A. G., Hussein, E., Ilka, H., Nima \& Rohini D. (2010). The immune Epitope Database 2.0. Nucleic Acid Research, 38, 854-862.

WHO. (2019). Human papillomavirus (HPV) and cervical cancer. [Downloaded at Agustus 2019]. https://www.who.int/ news-room/fact-sheets/detail/human-papillomavirus-(hpv)-and-cervical-cancer. 